\title{
EFFECTS OF CHOLERAGENOID AND GLUCOSE ON THE RESPONSE OF DOG INTESTINE TO ESCHERICHIA COLI ENTEROTOXINS
}

\author{
D. R. Nalin* and J. C. Mclaughlin $\dagger$ † \\ *Johns Hopkins Center for Medical Research, 550 North Broadway, Baltimore, \\ Maryland 21505 and University of Maryland; and \\ $\dagger \ddagger$ Cholera Research Laboratory, Dacca, Bangladesh
}

THE small intestine of the dog responds differently to the thermostable (ST) and the thermolabile (LT) enterotoxins of Escherichia coli (Nalin, Bhattacharjee and Richardson, 1974). In ligated jejunal loops, ST acts within minutes of contacting the mucosa and its effect ends when it is rinsed out of the loops. The effect of LT is detectable only after a lag of $3-4 \mathrm{~h}$ and is unchanged by rinsing the loops after exposure to the toxin. The differences in onset and duration of these ST and LT effects in dog intestinal loops permit the study of E. coli culture supernates containing ST, LT or both.

Culture supernates containing LT and concentrated 60- to 100 -fold invariably cause net fluid secretion in the dog intestinal loop. As the response to ST is more variable, ST from a series of strains was tested to establish quantitative criteria for its effect on absorption in the dog loop. As the characteristics of dog-loop responses to ST or LT produced by different strains remained constant, culture supernates derived from a single strain producing both ST and LT $\left(\mathrm{ST}^{+} / \mathrm{LT}^{+}\right)$were used to study the effect of glucose on absorption in toxintreated loops, and to determine whether the two enterotoxins are blocked by natural cholera toxoid (choleragenoid). The glucose effect has a clinical application in the oral glucose-saline therapy of non-cholera diarrhoeas (Nalin and Cash, 1970) whilst a possible choleragenoid effect is relevant to studies on the identity, or otherwise, of mucosal toxin-binding sites for enterotoxins of E. coli and Vibrio cholerae (Pierce, 1973).

\section{MATERIALS AND METHODS}

Strains of E. coli isolated from the faeces of 40 Bangalee patients with acute idiopathic diarrhoea were tested for LT by the Chinese hamster-ovary (CHO) cell assay (Guerrant et al., 1974). The effects on absorption of ST and LT produced by these strains were then tested in dog intestinal loops, to define the criteria for a positive ST response. Then the effects of glucose and choleragenoid on the ST and LT responses were determined.

Preparation of E. coli culture supernates. Pools of 10 colonies of $E$. coli were chosen from cultures on MacConkey's agar of rectal swabs obtained from patients before antibiotic therapy was begun. Clinical details of the patients have been reported (Nalin et al., 1975). Additional strains of $E$. coli from patients with diarrhoea were supplied by courtesy of $\mathrm{Dr}$ Doyle Evans. Isolates were stored at room temperature in the dark on blood-agar base slopes. The identification of $E$. coli was confirmed by standard biochemical tests. To

Received 18 Mar. 1977; revised version accepted 18 Nov. 1977

$\uparrow$ Present address: Division of Microbiology, Hartford Hospital, Conn., USA.

J. MED. MICROBIOL. - VOL. 11 (1978) 
prepare culture supernates, broth was inoculated with pooled isolates, except in a few cases noted in the text when sucrose-fermenting $(\mathbf{S}+)$ or sucrose-nonfermenting $(\mathbf{S}-)$ colonies from the pooled isolates were tested individually. Culture supernates for $\mathrm{CHO}$ assay were prepared as described previously (Nalin et al., 1975).

As net fluid loss in dog intestine occurs at high concentrations of ST (Pierce and Wallace, 1972), concentrated cell-free supernates were prepared from broth cultures of pooled isolates by the method of Evans, Evans and Gorbach (1973) at $p H$ 8. Supernates were concentrated approximately 60 - to 100 -fold (mean 73 -fold \pm 0.6 ; all figures for means in the text are accompanied by the standard error of the mean). Concentrates were hypotonic (4-50 m-osmole per litre), had low ammonia content (30-100 mg per litre) and when stored at $5^{\circ} \mathrm{C}$ retained their ST and LT activity for more than 1 year. Heated supernates of three strains were produced by heating at $100^{\circ} \mathrm{C}$ for $20 \mathrm{~min}$. in a boiling water bath and were tested after cooling to room temperature.

As the ST responses in dog intestine were similar, whether induced by supernates containing ST alone or both ST and LT, culture supernates of a single $\mathrm{ST}^{+} / \mathrm{LT}^{+}$strain (CRL10 400) were used to test for the effects of glucose and choleragenoid on the loop responses to both enterotoxins. Concentrated supernates derived from this strain had a mean protein concentration of $8 \cdot 29 \pm 0 \cdot 35 \mathrm{~g}$ per litre.

As CRL10 400 was also used as the positive control, Dr I. Craig and Dr A. Andremont kindly compared its toxigenicity with that of a typical ST +/LT - strain (CRL35 647) in the rabbit-skin and suckling-mouse tests (Dean et al., 1972; Evans et al., 1973). The tests were carried out on supernates from unheated and shaken aerobic cultures grown in casamino acid-yeast extract medium. ST was expressed in "effective doses" (ED per ml) and LT in " 4-mm blueing" doses (BD4 per $\mathrm{ml}$ ). One ED is defined as the amount yielding a ratio of gut-weight to remaining body weight of 0.1 in the suckling-mouse assay. Dose-response titrations were performed to obtain ED per $\mathrm{ml}$ and BD4 per ml endpoints.

Reference numbers of CRL (Cholera Research Laboratory) stock cultures of $E$. coli isolates are given below to facilitate comparison in other laboratories. ST $+/ \mathbf{L T}+$ : 10400 , 20 476(S+), 35 639, 35 671, 35 678, 35 687, 35 760, 35 875, 35 880, $36004(\mathbf{S}+)$; ST +/LT - : 20 178(S+), 20 546(S+), 20 580(S+), 20 590, 35 631, 35 642, 35 647, 36000.41 591, 41 736; ST-/LT - : $19487(\mathrm{~S}-), 19521,19587,19632,20483(\mathrm{~S}-), 20546(\mathrm{~S}-), 20$ 902, 20913 , 22 141, 22 205, 35 622, 35 733, 35 766, 35 797, 35 981, 36 013, 40 835, 41 251, 41 575, 41788. The toxigenic stock strains have all retained their toxigenicity over the period of 3 to 7 years during which they have been used to make supernates for testing in dogs.

Net water and sodium flux measurements in dog intestinal loops. Dogs were fasted overnight and kept lightly anaesthetised with intravenous sodium pentobarbital. At laparotomy, four or six ligated cannulated-jejunal or -ileal loops were constructed in each dog, as previously described (Nalin et al., 1974). The mean loop length was $17+0.3 \mathrm{~cm}$ and basal loop absorption was measured with a test solution of $\mathrm{NaCl} 150 \mathrm{~m}$.moles per litre $(300 \mathrm{~m}$.osmoles per litre; $p \mathrm{H} \mathrm{6.9)} \mathrm{containing} \mathrm{phenolsulphonphthalein} \mathrm{(PSP)} 50 \mathrm{mg}$ per litre or polyethylene glycol (PEG) $10 \mathrm{~g}$ per litre as a non-absorbable marker. After rapid intraluminal injection and mixing, a zero time sample was collected and a second sample was obtained on emptying the loops at the end of each 10-min. test period. Changes in water or sodium absorption or both were calculated from changes in marker and sodium concentrations over successive 10-min. periods. Sodium concentrations were measured with a flame photometer, PSP was measured spectrophotometrically after alkalinisation and PEG was measured by the turbidimetric method (Hydén, 1956).

In each instance basal absorption was measured first and the effect of ST was measured by repeating the test procedure after mixing supernates with the marker-test solution and injecting the mixture intraluminally through the cannula. Total volumes injected in the control and toxin periods were equal. After a 10-min. exposure to supernate-test solution mixtures, the loops were drained and absorption was measured again. After this, the loops were rinsed with physiological saline at $37^{\circ} \mathrm{C}$. The effect of LT was detected by measuring changes in absorption over a 4-h period after exposure to supernates. Toxic and non-toxic supernates were randomly distributed in adjacent loops. 
Studies with glucose. The effects of glucose on ST and LT responses were studied separately. In respect of ST, the effect of glucose on sodium absorption was examined by comparing control and experimental loops. In control loops, net absorption was measured for the saline test solution without glucose before, during and after the exposure to ST. The action of ST was stopped by rinsing the loops out $20 \mathrm{~min}$. after injection of the supernates. In experimental loops the procedure was the same, except that the test solution contained $110 \mathrm{~m}$.moles glucose per litre. This glucose concentration was chosen because it is optimal for enhancement of intestinal absorption in patients with diarrhoea (Nalin and Cash, 1973).

In respect of LT, absorption was monitored after exposure to supernates until net secretion appeared some 3-4 h after the ST effect had ended. Then the rate of net loop secretion was measured in successive 10-min. periods for a total of $30 \mathrm{~min}$., by means of the $\mathrm{NaCl}$ test solution without glucose. The same procedure was repeated, first with added glucose and finally without glucose. The effect of glucose on the response to LT was determined by comparing absorption in the presence of glucose with the mean absorption before and after the periods when glucose was present.

Choleragenoid studies. The effect of pre-treatment with choleragenoid on the response to ST and LT was tested after rinsing the loops with normal saline at $37^{\circ} \mathrm{C}$. Then a mean of $149 \mu \mathrm{g}$ (range 125-190 $\mu \mathrm{g}$ ) of choleragenoid in $10 \mathrm{ml}$ of normal saline (three loops) or distilled water (three loops) was injected intraluminally. The choleragenoid (Finkelstein, Fujita and Lospalluto, 1971), kindly supplied by Dr R. Finkelstein, was freshly reconstituted from lyophilised material. Control loops received $10 \mathrm{ml}$ physiological saline or distilled water to correspond with the diluent of the choleragenoid given to adjacent test loops.

After $3 \mathrm{~h}$, both control and choleragenoid solutions had been absorbed and baseline net-water fluxes were measured as described above. In choleragenoid studies, $4 \mathrm{ml}$ of a culture supernate of strain CRL10 400 concentrated 100-fold were mixed with $8 \mathrm{ml} \mathrm{NaCl}$ PEG test solution and injected intraluminally into all loops. After mixing, a zero-time specimen was taken and $10 \mathrm{~min}$. later the residual loop fluid was withdrawn for analysis. Net water fluxes were determined from changes in marker concentrations. A second 10-min. net-water flux measurement was made to detect any ST effect and the loops were again rinsed to remove any unbound toxin. Serial net fluxes were then measured in the same way by means of the test solution alone at intervals up to $6 \mathrm{~h}$, to determine the effect of choleragenoid on LT.

\section{RESULTS}

In tests with culture supernates of 40 strains of $E$. coli, 10 strains induced both ST and LT responses, 10 induced only ST responses, and the rest induced neither response (see fig. 1 and strain reference list above). Supernates containing ST showed a rapid, significant decrease in absorption within $20 \mathrm{~min}$. of contact of mucosa with the supernate, whereas with LT net secretion began after 3-4 h. The CHO cell-assay results for LT were in agreement with the LT responses in dog ileal loops. No strain tested produced LT alone.

\section{ST response}

Supernates classified as $\mathrm{ST}^{+}$decreased absorption by at least $50 \%$ of basal loop-absorption rate, within $20 \mathrm{~min}$. of intraluminal injection of heated or unheated concentrated supernates. As loops varied in baseline absorption rate, it was convenient to express the ST effect as a percentage decrease in absorption relative to baseline ( \pm SEM), as well as to record absolute values for decrease in absorption (table ). 
TABLE

Comparison of the effects of ST-containing culture supernates with the effects of control supernates on dog ileal-loop absorption

\begin{tabular}{|c|c|c|c|c|c|}
\hline \multirow{2}{*}{$\begin{array}{c}\text { Test } \\
\text { supernate }\end{array}$} & \multicolumn{2}{|c|}{ Number of } & \multicolumn{2}{|c|}{ Absorption (ml $\mathrm{H}_{2} \mathrm{O}$ per 10 min. per loop) } & \multirow[b]{2}{*}{$\begin{array}{l}\text { Significance } \\
\text { (P) }\end{array}$} \\
\hline & strains & $\begin{array}{l}\text { ileal } \\
\text { loops }\end{array}$ & Mean (and range) & $\begin{array}{l}\text { Percentage change } \\
\text { (and range) }\end{array}$ & \\
\hline $\begin{array}{l}\text { ST+/LT- } \\
\text { ST+/LT- } \\
\text { ST-/LT- } \\
\text { None }\end{array}$ & $\begin{array}{r}9 \\
1 \\
21 \\
0\end{array}$ & $\begin{array}{r}21 \\
11 \\
24 \\
7\end{array}$ & $\begin{array}{l}-1.6 \pm 0.2(-0.4 \text { to }-4 \cdot 0) \\
-1.5 \pm 0.24(-0.4 \text { to }-2.4) \\
+0.23 \pm 0.05(-0.2 \text { to }+0.8) \\
+0.4 \pm 0.09(+0.2 \text { to }+0.7)\end{array}$ & $\begin{array}{l}-123 \pm 6(-57 \text { to }-218) \\
-122 \pm 10(-80 \text { to }-114) \\
+27 \pm 7(-17 \text { to }+125) \\
+53 \pm 23(+8 \text { to }+64)\end{array}$ & $\begin{array}{l}\leqslant 0.001 \\
\leqslant 0.001 \\
\leqslant 0.001 \\
\leqslant 0.01\end{array}$ \\
\hline
\end{tabular}

Net secretion can clearly occur only in loops with a decrease in absorption greater than $100 \%$. It could be detected after aspiration without measuring marker concentration changes in loops with decreases in absorption greater than $-110 \%$ of baseline. In 18 of 38 loops showing the ST response, net secretion did not occur despite decreases in net absorption averaging $-0.85 \pm$ $0 \cdot 13 \mathrm{ml}$ per $10 \mathrm{~min}$. per loop ( $-69 \pm 5 \%$ of baseline; $P \leqq 0.001)$.

Three of the ST+/LT - supernates were tested in dogs before and after heating and gave the same results (fig. 1). Supernates from a given strain also gave similar results in different dogs (table).

There was almost no overlap between the effects of ST $+/ \mathrm{LT}-$ and control ST $-/$ LT - strains; insignificant decreases of absorption of $-12 \%$ and $-17 \%$ of baseline occurred in only two of 24 loops receiving non-toxic supernates. The response of the other 22 loops was similar to that of control loops in seven dogs given no supernates; in these absorption increased above the baseline whereas ajacent loops treated with ST showed decreases in absorption. The increased absorption after exposure to ST-/LT - supernates was expected because of their hypotonicity. Control loops given no supernates as well as loops given $\mathrm{ST}-/ \mathrm{LT}$ - supernates, continued to absorb during the remainder of the experimental period (fig. 1). Thus, under the conditions of this study, the ST response may be defined as a decrease in absorption of $\geqq 50 \%$, taking place within $20 \mathrm{~min}$. of exposing the loops to concentrated $E$. coli culture supernates and ending within $20 \mathrm{~min}$. of rinsing out the loop.

Suckling-mouse and rabbit-skin assays showed that the ST content of unheated shaken-culture filtrates of strain CRL35 647 was 912 ED per ml whereas the LT content of these filtrates was $10 \mathrm{BD} 4$ per $\mathrm{ml}$ or less. By comparison, filtrates of strain CRL10 400 had an ST content of $800 \mathrm{ED}$ per ml and an LT content of 400-500 BD4 per ml. The ST content of filtrates from these strains was similar and was consistent with the quantitatively-similar ST responses in loops exposed to their culture supernates.

\section{The effect of glucose on absorption}

As ST production and the intestinal response to ST from ST $+/ \mathbf{L T}-$ and ST $+/$ LT + strains grown under identical conditions were similar, supernates 
from a single ST +LT + strain (CRL10 400) were used to compare the effect of glucose on ST and LT responses. Glucose enhanced sodium absorption and reduced the net luminal-sodium accumulation brought about by both ST and LT (fig. 2). Glucose increased absorption by $49 \pm 7 \mu \mathrm{Eq}$ per $10 \mathrm{~min}$. per loop during the ST effect and by $72 \pm 3 \mu \mathrm{Eq}$ per loop during the LT effect. The glucose effect in toxin-treated loops was slightly less than in control loops without toxin ( $77 \pm 20 \mu \mathrm{Eq}$ per $10 \mathrm{~min}$. per loop), but this difference was not statistically significant.

\section{The choleragenoid blockade of LT}

Pre-treatment of loops with natural choleragenoid had no effect on a subsequent ST response but completely blocked the LT response (fig. 3). In both control and choleragenoid-treated loops the ST response began within $20 \mathrm{~min}$. and was not affected by choleragenoid. In choleragenoid-treated loops
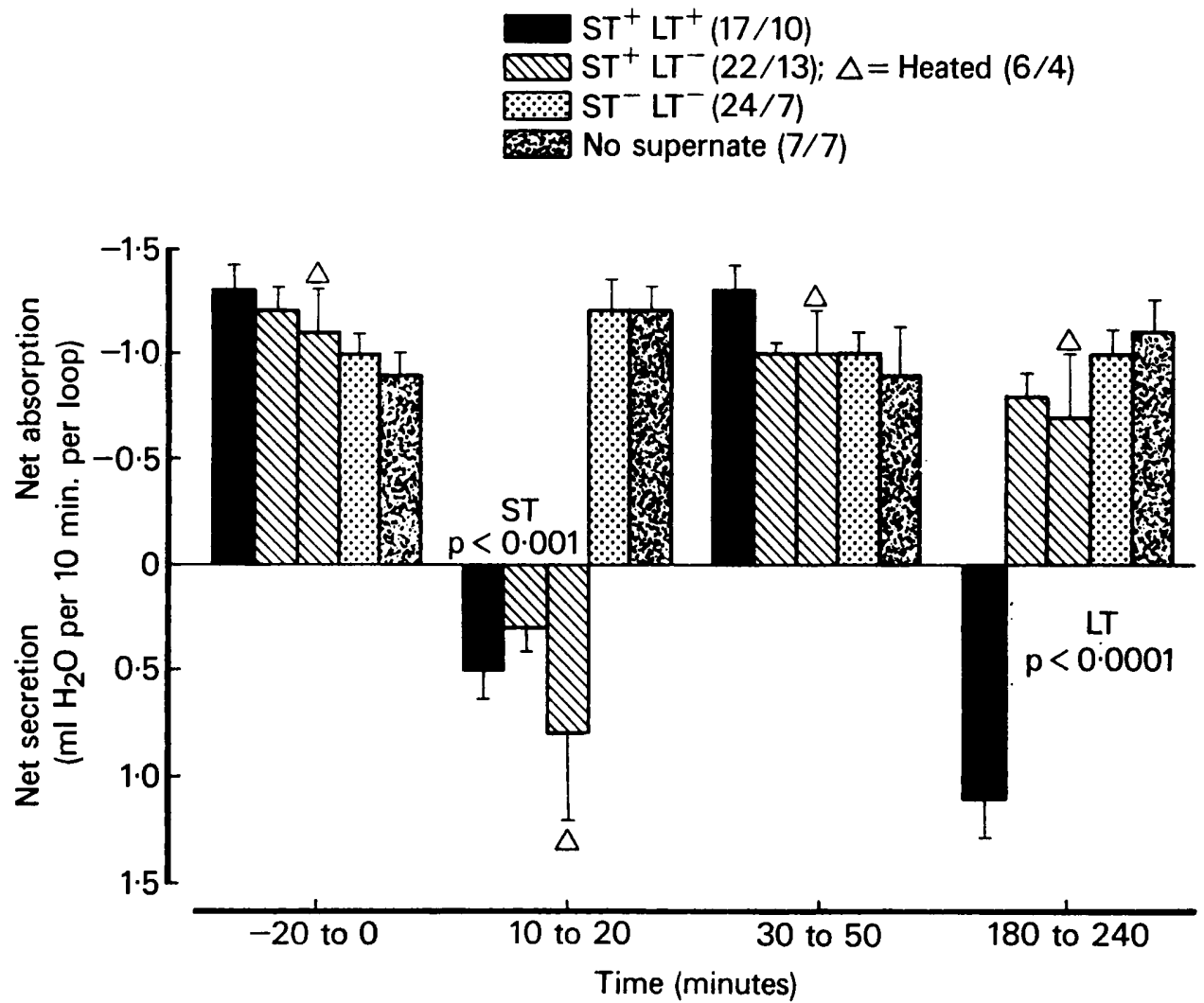

FIG. 1.-Effects of $E$. coli culture supernates on absorption. Bars above line = decrease in loop water (absorption from loop). Bars below line = increase in loop water (net secretion into loop). All loops absorbed normally before exposure to supernates ( -20 to $0 \mathrm{~min}$.) and absorption continued in untreated loops and in loops treated with non-toxic supernates. Absorption fell within $20 \mathrm{~min}$. of exposure to ST+ supernates, and recovered after rinsing. Supernates that contained LT produced net secretion 3-4 h later. Numbers in parentheses = number of loops/ number of dogs. 


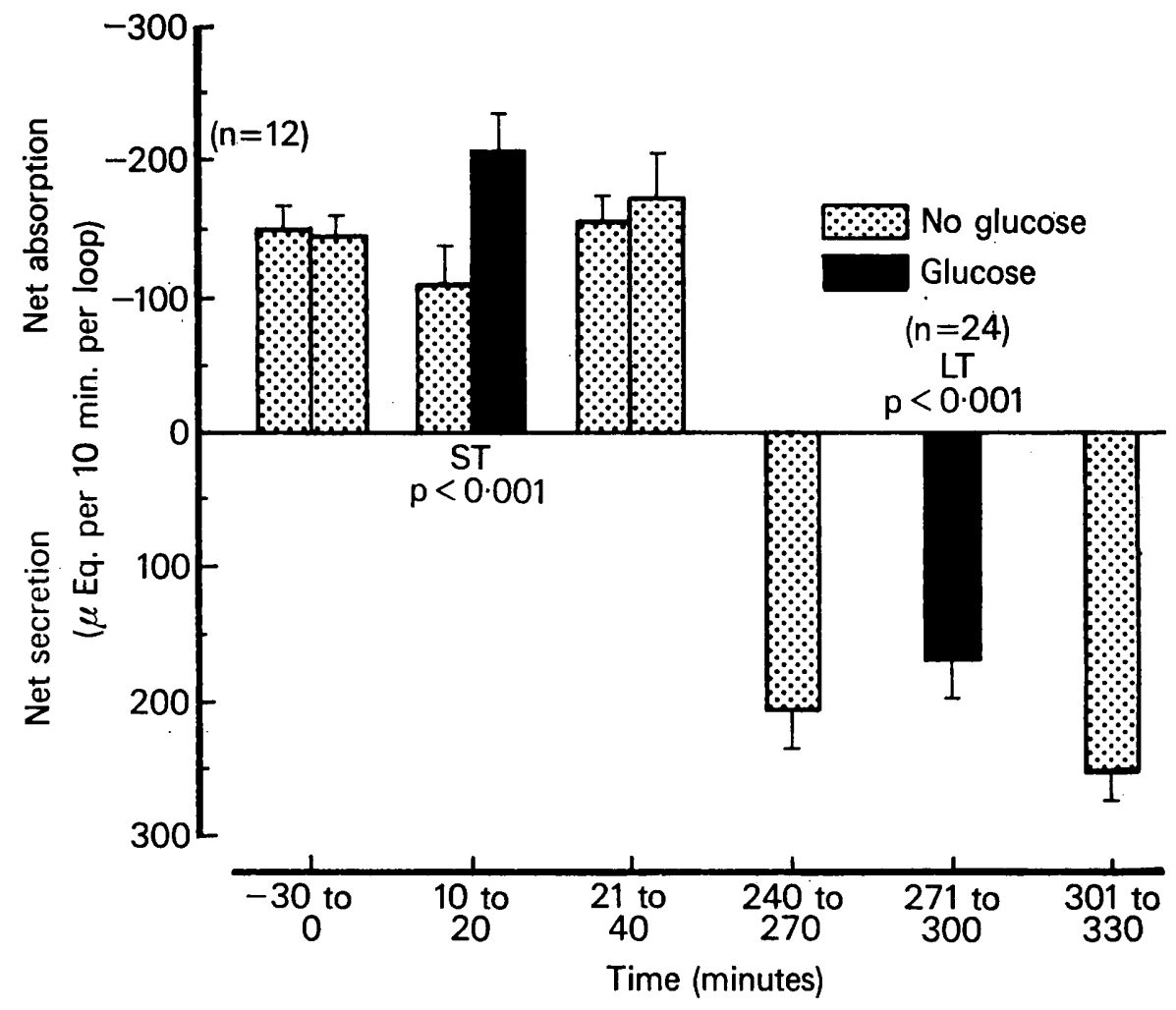

FIG. 2.-Addition of glucose to test fluid (black bars) increased net sodium absorption (or reduced net sodium secretion) during both ST and LT effects. $n=$ Number of loops represented by each bar.

absorption returned to normal within $20-40 \mathrm{~min}$. of rinsing and remained normal during the 6-h observation period. The LT response, however, developed only in control loops. In two loops given $225 \mu \mathrm{g}$ and $300 \mu \mathrm{g}$ of glutaraldehyde-treated cholera toxoid (Wyeth) no blocking effect was seen and baseline absorption changed to secretion after giving toxin. The mean secretion was $-0.4 \mathrm{ml}$ per $10 \mathrm{~min}$. per loop for both ST and LT responses.

\section{DISCUSSION}

Recent work has suggested that the effects of glucose and choleragenoid on the responses to $E$. coli and cholera enteroxins are different (Pierce, 1973; Holmgren, 1973a; Sherr et al., 1973). However, in these reports the effects of $E$. coli ST and LT toxins were not usually distinguished. In the present study the different responses of dog small bowel to ST and LT were used to reexamine the glucose and choleragenoid effects. The results indicate that glucose enhances absorption during both ST and LT responses, and that choleragenoid blocks the LT but not the ST response. These data constitute additional evidence for the similarity of LT, but not of ST, to cholera toxin, as first suggested by work with enterotoxins from porcine strains of $E$. coli (Gyles and Barnum, 1969; Smith and Gyles, 1970). 


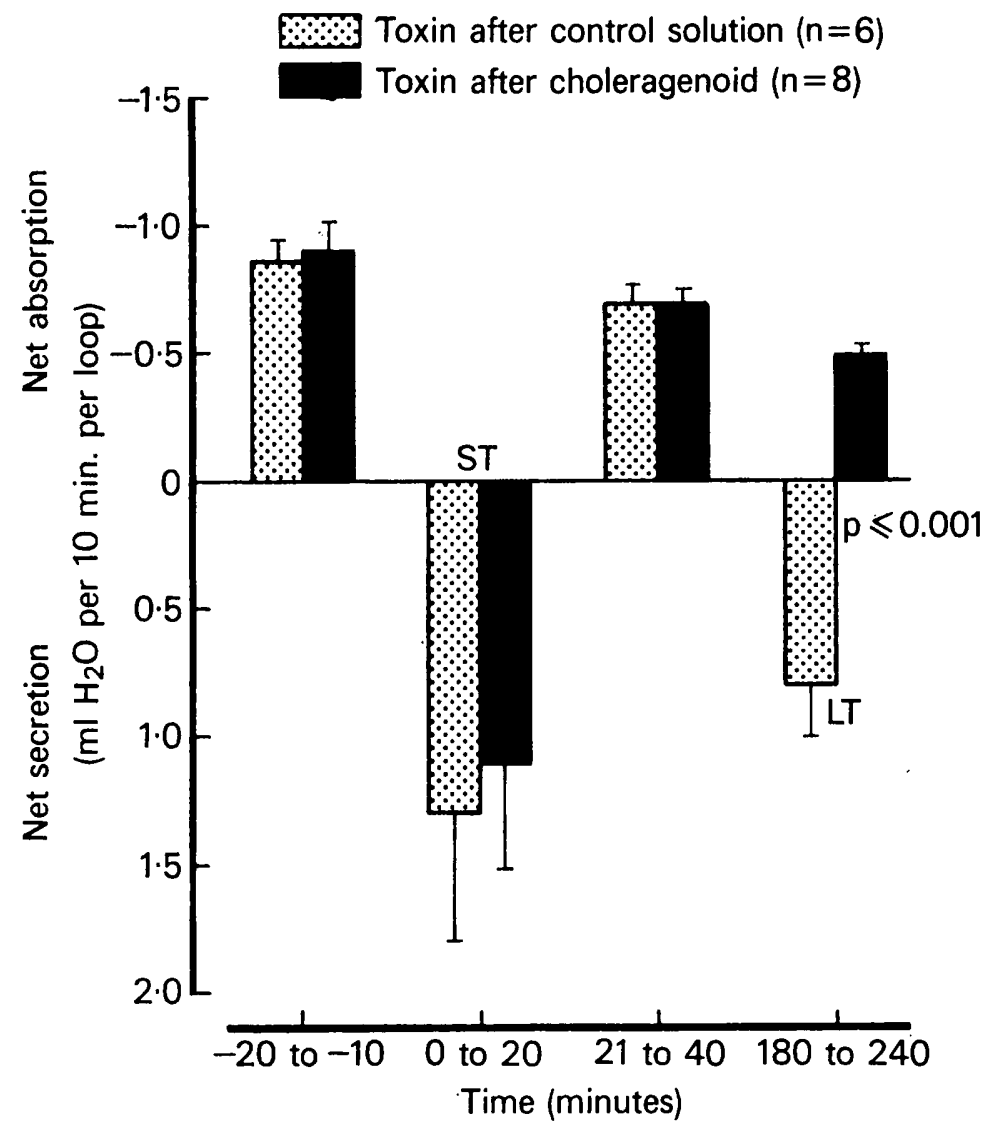

FrG. 3.-The blocking action of choleragenoid on LT but not on ST. ST produced fluid accumulation (bars below line) within $20 \mathrm{~min}$. in both control and choleragenoid-treated loops. Absorption (bars above line) returned to normal 20-40 min. after rinsing loops. In controls, but not in choleragenoid-treated loops, the LT effect became evident 3-4 h later. $n=$ Number of loops represented by each bar.

Our findings extend to LT-treated loops earlier observations on the efficacy of glucose in ST-treated loops (Pierce and Wallace, 1972), and show that, as in the case of cholera toxin (Carpenter, Sack and Feeley, 1968), the glucose effect is independent of the effects of the enterotoxins. Whipp and Moon (1973) reported that glucose increased absorption in loops infected with enteropathogenic $E$. coli serotypes but the type of toxin produced was not specified. The effect of glucose in the present study is consistent with the efficacy of oral glucose-electrolytes solutions in tropical diarrhoeas (Nalin and Cash, 1970; Sack et al., 1970) which are known to be associated with enterotoxigenic $E$. coli Sack et al., 1971; Pierce and Wallace, 1972; Nalin et al., 1974; Nalin et al., 1975; Sack et al., 1975).

As choleragenoid, like the cholera toxin molecule, binds to cell receptors (Holmgren, 1973b), the blocking of $E$. coli LT by choleragenoid suggests a common binding site and common toxin-binding sub-unit for cholera toxin and for E. coli LT. Conversely failure of choleragenoid to block the ST 
response implies a separate binding site for ST. This indicates different mechanisms of action for ST and LT, a suggestion that is supported not only by their differing pathophysiological effects but also by a recent report showing that ST, unlike LT or cholera toxin, does not stimulate adenylate cyclaserelated phenomena such as platelet aggregation (Fumarola, 1976).

The difference between the present results and previous reports of a lack of choleragenoid effect on $E$. coli enterotoxin (Holmgren, 1973a; Pierce, 1973) may be explained by the lack of differentiation of LT and ST effects in the earlier work. It is possible that, in addition, other factors may have played a role, such as the lower doses of choleragenoid used and species differences between the dog and the rabbit. The absence of an effect with glutaraldehydetreated cholera toxoid is attributable to structural differences between it and choleragenoid, and is consistent with the ability of choleragenoid, but not gluteraldehyde-treated toxoid, to block cholera toxin (Pierce, 1972).

It is worthy of note that strains of enterotoxigenic E. coli producing only LT, such as those reported elsewhere (Morris et al., 1975), were not detected in our series nor in another series reported from the same area (Ryder et al., 1976). Only four such strains have been reported from Bangladesh, in a study of $E$. coli from 65 patients (Sack et al., 1977), based on Y-1 adrenal-cell assay for LT and a negative suckling-mouse test for ST. This suggests that geographical differences may exist in the prevalence of strains producing particular enterotoxins, and that strains producing LT alone are relatively uncommon in Bangladesh. Furthermore, it has been shown recently that under certain storage conditions, stock strains that are $\mathrm{LT}+/ \mathrm{ST}+$ revert to $\mathrm{LT}+/ \mathrm{ST}-$, possibly by loss of a plasmid (Evans et al., 1977). Therefore, the true nature of $\mathrm{LT}+/ \mathrm{ST}$ - strains remains to be defined by comparative studies of their culture supernates in different in-vivo and in-vitro models.

The fact that $47 \%$ of ST +/LT - supernates reduced absorption by more than $57 \%$ without causing net secretion also suggests that use of net secretion as the only criterion for enterotoxicity may result in failure to detect significant absorptive decreases, particularly those caused by ST. As the suckling mouse test for ST depends only on net fluid accumulation, the question arises as to whether in the mouse, as in the dog, some strains that produce ST may go unrecognised when absorptive decreases are not measured. Preliminary evidence (Bergquist, Levine and Nalin, 1977) suggests that this is so.

\section{SUMMARY}

Culture supernates of Escherichia coli from diarrhoea patients were tested in dog jejunal loops for thermostable (ST) and thermolabile (LT) enterotoxins. Pre-treatment with choleragenoid blocked LT but not ST. Glucose was found to reduce fluid accumulation induced by both types of enterotoxin. The findings confirm and extend previous evidence of similarities between cholera toxin and $E$. coli $\mathrm{LT}$ and differences between it and $E$. coli $\mathrm{ST}$.

This study was funded by NIH research agreement R07 A110 04815 with the Johns Hopkins Center for Medical Research and by NIAID research agreement N01 AI42 553 
with the University of Maryland. The Cholera Research Laboratory (CRL) is an autonomous organisation created by agreement between the Governments of the People's Republic of Bangladesh and the United States of America. It received its basic support from these governments and from the Governments of the United Kingdom and Australia. The research described in this paper was done with the above support. We thank the staffs of the Matlab and Dacca Cholera Hospitals and the microbiology, serology, chemistry and animal facility sections of the Cholera Research Laboratory for their invaluable assistance.

\section{REFERENCES}

Bergquist, E. J., Levine, M. M. and Nalin, D. R. 1977. Relative sensitivity of dog and infant mouse assays for thermostable Escherichia coli enterotoxin. Proc. 17th Interscience Conf. on Antimicrob. Agents Chemother., abstract 361.

Carpenter, C. C. J., Sack, R. B. AND Feeley, J. C. 1968. Site and characteristics of electrolyte loss and effect of intraluminal glucose in experimental canine cholera. J. clin. Invest., 47, 1210.

Dean, A. G., Ching, Y. C., Williams, R. G. And Harden, L. B. 1972. Test for Escherichia coli enterotoxin using infant mice: application in a study of diarrhea in children in Honolulu. J. infect. Dis., 125, 407.

Evans, D. J., Evans, D. G. AND GoRbach, S. L. 1973. Production of vascular permeability factor by enterotoxigenic Escherichia coli isolated from man. Infect. Immun., 8, 725.

Evans, D. J. JR, Evans, D. G., TJoa, W. S. and Dupont, H. L. 1977. Relationships between colonization factor production, serotype and enterotoxigenicity in Escherichia coli pathogenic for man. Proc. 17th Interscience Conf. on Antimicrob. Agents Chemother., abstract 400.

Finkelstein, R. A., Fujita, K. And Lospalluto, J. J. 1971. Procholeragenoid: an aggregated intermediate in the formation of choleragenoid. J. Immun., 107, 1043.

Fumarola, D. 1976. On the possible implications of platelets as a cell system useful for the detection of enteropathogenicity of $E$. coli and other enterobacteria. Prog. Med., Roma, 32, 517.

Guerrant, R. L., Brunton, L. L., Schnaitman, T. C., Rebhun, L. I. and Gilman, A. 1974. Cyclic adenosine monophosphate and alteration of Chinese hamster ovary cell morphology: a rapid, sensitive in vitro assay for the enterotoxins of Vibrio cholerae and Escherichia coli. Infect. Immun., 10, 320.

Gyles, C. L. AND BARnum, D. A. 1969. A heat labile enterotoxin from strains of Escherichia coli enteropathogenic for pigs. J. infect. Dis., 120, 419.

Holmgren, J. 1973a. Comparison of the tissue receptors for Vibrio cholerae and Escherichia coli enterotoxins by means of gangliosides and natural cholera toxoid. Infect. Immun., 8,851 .

Holmgren, J. 1973b. Proc. 95th Joint Conf. on Cholera, U.S.-Japan Cooperative Medical Science Program, Dept of State publ. 8762, p. 196.

HYDÉN, S. 1956. The recovery of polyethylene glycol after passage through the digestive tract. Lantbr-Högsk. Annlr, 22, 411.

MorRIS, G. K. et al. 1975. Laboratory investigation of diarrhea in travellers to Mexico: evaluation of methods for detecting enterotoxigenic Escherichia coli. J. clin. Microbiol., 3, 486.

Nalin, D. R., Bhattacharjee, A. K. and Richardson, S. H. 1974. Cholera-like toxic effect of culture filtrates of Escherichia coli. J. infect. Dis., 130, 595.

NaLin, D. R. AND CASH, R. A. 1970 . Oral or nasogastric maintenance therapy for diarrhoea of unknown aetiology resembling cholera. Trans. R. Soc. trop. Med. Hyg., 64, 769.

NALIN, D. R. AND CASH, R. A. 1973. The optimal oral therapy formula for cholera and cholera-like diarrhoeas. Proc. 6th Int. Epidem. Ass. Meeting, Belgrade, p. 1048.

Nalin, D. R., Mclaughlin, J. C., Rahaman, M., Yunus, M. and CuRlin, G. 1975. Enterotoxigenic E. coli and idiopathic diarrhea in Bangladesh. Lancet, 2, 1116. 
PIERCE, N. F. 1973. Differential inhibitory effect of cholera toxoid and ganglioside on the enterotoxins of Vibrio cholerae and Escherichia coli. J. exp. Med., 137, 1009.

Pierce, N. F. AND Wallace, C. K. 1972. Stimulation of jejunal secretion by crude Escherichia coli enterotoxin. Gastroenterology, 63, 439.

RYDER, R. W. et al. 1976. Enterotoxigenic Escherichia coli and reovirus-like agents in rural Bangladesh. Lancet, 1, 659.

SACK, R. B. et al. 1970. The use of oral replacement solutions in the treatment of cholera and other severe diarrheal disorders. Bull. Wld Hlth Org., 43, 351.

Sack, R. B., Gorbach, S. L., Banwell, J. G., Jacobs, B., Chatterjee, B. D. And Mitra, R. C. 1971. Enterotoxigenic Escherichia coli isolated from patients with severe choleralike disease. J. infect. Dis., 123, 378.

SAck, D. A., Merson, M. H., Wells, J. G., SAck, R. B. ANd Morris, G. K. 1975. Diarrhea associated with heat-stable enterotoxin-producing strains of Escherichia coli. Lancet, 2, 239.

Sherr, H. P., Banwell, J. G., Rothfeld, A. and Hendrix, T. R. 1973. Pathophysiologic response of rabbit jejunum to Escherichia coli enterotoxin. Gastroenterology, 65, 895.

SMITH, H. W. AND GYLES, C. L. 1970. The relationship between two apparently different enterotoxins produced by enteropathogenic strains of Escherichia coli of porcine origin. J. med. Microbiol., 3, 387.

WhIPP, S. C. AND MoON, H. W. 1973. Modification of enterosorption in experimental enteric colibacillosis of swine inoculated with Escherichia coli. J. infect. Dis., 127, 255. 